\title{
Cracking the epitranscriptome
}

\author{
SCHRAGA SCHWARTZ \\ Department of Molecular Genetics, Weizmann Institute, Rehovot 76100, Israel
}

\begin{abstract}
Over 100 distinct chemical modifications can be catalyzed on RNA post-synthesis, potentially serving as a post-transcriptional regulatory layer of gene expression. This review focuses on recent advances, knowledge gaps, and challenges pertaining to N6methyladenosine (m6A), an abundant modification of mRNA for which substantial progress has been made in recent years. The discussed aspects are also very relevant for a wide range of additional modifications on mRNA collectively coined the epitranscriptome.
\end{abstract}

Keywords: N6-methyladenosine; epitranscriptome; review

RNA can be post-transcriptionally modified with over 100 chemically distinct modifications (Machnicka et al. 2013), each catalyzed by one or more often highly conserved (Anantharaman et al. 2002) enzymes. In an analogous manner to modifications occurring post-synthesis on proteins (e.g., phosphorylation, ubiquitination) or on DNA (e.g., 5-methylcytosine), chemical modifications on RNA-and particularly within mRNA-harbor the exciting potential of fine-tuning and regulating the properties of the RNAs harboring them. In recent years, there have been substantial advances in our understanding of the whereabouts, the nature, and the roles of modifications on mRNA. While the focus of this review is primarily on advances, knowledge gaps, and challenges pertaining to N6-methyladenosine (m6A), the discussed aspects are also very relevant for a wide range of additional modifications on mRNA, of which we know even less, collectively coined the "RNA epigenome" (He 2010) or "epitranscriptome" (Meyer et al. 2012; Saletore et al. 2012).

RNA was recognized to be modified from the early days of RNA research (Cohn and Volkin 1951; Davis and Allen 1957). Roughly two decades later, one particular modification, N6-methyladenosine, was found to be abundant at high levels within mRNAs (Desrosiers et al. 1974; Perry and Kelley 1974; Lavi and Shatkin 1975; Wei et al. 1975, 1976). Nonetheless, the overwhelming majority of research on RNA modification was limited to three classes of highly expressed and catalytically active RNAs_rRNA, tRNA, and snRNAs (Greenberg and Penman 1966; Grosjean et al. 1998). This is attributable to technical challenges in mapping RNA modifications within the relatively lowly expressed

Corresponding author: schwartz@weizmann.ac.il

Article and publication date are at http://www.rnajournal.org/cgi/doi/10. 1261/rna.054502.115.
mRNAs, which severely limited the ability to dissect their role. The general notion that seems to have prevailed in the field was that RNA modifications was a phenomenon primarily limited to a few types of highly structured molecules, within which it was likely a constitutive, "basal" feature.

The revived interest in RNA modifications over recent years is due to two major advances. First, biochemical approaches coupled with RNA sequencing have made it possible to map certain RNA modifications in a transcriptome-wide manner. Initial protocols for transcriptomewide mapping of m6A were achieved by using an anti-m6A antibody to immunoprecipitate methylated RNA fragments, followed by sequencing of the RNA (Dominissini et al. 2012; Meyer et al. 2012). Obtaining these maps has been of crucial importance, as they have (i) allowed the uncovering of specific genomic regions in which m6A was enriched in mRNAs (Dominissini et al. 2012; Meyer et al. 2012; Ke et al. 2015) or in microRNAs (Meyer et al. 2012; Chen et al. 2015; Alarcón et al. 2015b), allowing the generation of testable hypotheses concerning the role of this modification; (ii) shown that methylated sites are evolutionarily conserved between human and mouse (Dominissini et al. 2012; Meyer et al. 2012; Batista et al. 2014), suggesting that m6A has a conserved function; (iii) allowed addressing the dynamics of the modification, revealing that in certain systems, such as in yeast meiosis, m6A is highly dynamic (Schwartz et al. 2013), whereas in other assayed conditions, such as in immune response to LPS or differentiation, the overall topologies appear to be stable (Batista et al. 2014; Schwartz et al. 2014b; Geula et al. 2015); and (iv) made it feasible to perturb

(C) 2016 Schwartz This article is distributed exclusively by the RNA Society for the first 12 months after the full-issue publication date (see http:// rnajournal.cshlp.org/site/misc/terms.xhtml). After 12 months, it is available under a Creative Commons License (Attribution-NonCommercial 4.0 International), as described at http://creativecommons.org/licenses/by-nc/4.0/. 
individual methylated sites on mRNAs (Schwartz et al. 2013) and to quantify m6A levels at physiologically methylated sites in mRNA (Liu et al. 2013b), although to date studies have not yet been able to link perturbations at individual m6A sites to physiological roles.

A second, major advance in recent years has been in our understanding of the players involved in encoding ("writing"), decoding ("reading"), and removing ("erasing") of m6A. Until five years ago, only a single factor-METTL3involved in m6A catalysis was known, though it was recognized already at the time that this gene formed part of a larger $200 \mathrm{kDa}$ complex required for m6A catalysis (Bokar et al. 1997). Over recent years, at least eight additional components involved in encoding and decoding methylations have been identified, including three additional m6A "writing" components (METTL14, WTAP, and KIAA1429) in mammals (Liu et al. 2013a; Ping et al. 2014; Schwartz et al. 2014b; Wang et al. 2014b) and two in yeast (Agarwala et al. 2012); two m6A "erasers" (FTO and ALKBH5) (Jia et al. 2011; Zheng et al. 2013); and a class of m6A "readers" encompassing at least three human paralogs (YTHDF1, YTHDF2, and YTHDF3) (Dominissini et al. 2012; Li et al. 2014; Schwartz et al. 2014b; Wang et al. 2014a, 2015; Zhu et al. 2014), conserved in their ability to bind methylated RNA also in yeast (Schwartz et al. 2013). Recently, also hnRNP proteins have been implicated as $\mathrm{m} 6 \mathrm{~A}$ readers, both through direct binding of m6A (Alarcón et al. 2015a) or indirectly, in a structuremediated manner (Liu et al. 2015).

Perturbation of these factors has implicated these genesand by inference, $\mathrm{m} 6 \mathrm{~A}$ - in playing critical roles in a variety of systems. Specifically, experimental elimination of METTL3 or METTL14 in human or mouse embryonic stem cells abolishes the ability of cells to terminate their naive state and to differentiate, leading to restricted lineage priming and embryonic lethality (Batista et al. 2014; Geula et al. 2015). Early embryonic lethality is also observed upon loss of WTAP in mouse (Horiuchi et al. 2006, 2013), and defects in early development or gametogenesis are also observed upon perturbation of m6A writers in yeast meiosis (Shah and Clancy 1992; Clancy et al. 2002; Agarwala et al. 2012; Schwartz et al. 2013), Drosophila oogenesis (Hongay and Orr-Weaver 2011), and plants (Zhong et al. 2008; Bodi et al. 2012). Further, depletion of METTL3 elicited circadian period elongation (Fustin et al. 2013). The two m6A demethylases are also associated with pronounced phenotypes: Mutations in FTO lead to severe growth retardation and multiple congenital abnormalities in human (Boissel et al. 2009), and FTO-deficient mice suffer from growth retardation and reduced body mass (Fischer et al. 2009). FTO depletion also resulted in impaired differentiation of pre-adipocytes, whereas differentiation was enhanced upon depletion of METTL3 (Zhao et al. 2014). ALKBH5 depletion results in impaired fertility in mice (Zheng et al. 2013). To date, the $\mathrm{m} 6 \mathrm{~A}$ readers have only been associated with phenotypes in yeast, where deletion of MRB1/Pho92 results in decreased growth on nonfermentable carbon sources (Kang et al. 2014) and delayed sporulation (Schwartz et al. 2013).

Importantly, integration of these two advances-i.e., overlaying m6A maps with molecular readouts (e.g., RNA levels, RNA stability, translational efficiency) following perturbation of newly discovered components of the methylation machinery-has proven to be a particularly effective strategy for beginning to unravel the molecular role of m6A. Research by the He laboratory, focusing on the m6a "reader" YTHDF2, established its role in destabilization of methylated messages, and showed that messages bound by YTHDF2 localize to $\mathrm{P}$ bodies (Wang et al. 2014a). Additional support for a role in RNA destabilization was found in other studies (Schwartz et al. 2014b; Wang et al. 2014a,b; Geula et al. 2015). The He laboratory further demonstrated that YTHDF1 also binds to m6A and increases translational efficiency (Wang et al. 2015). The Pan group has highlighted a different mode of action for m6A-by directly affecting RNA structure. They found that m6A destabilizes the RNA duplexes, leading methylated mRNAs to be more accessible to binding by the RNA binding protein HNRNPC (Liu et al. 2015). Support for decreased secondary structure at methylated sites was also found by the Chang group, which overlaid transcriptome-wide in vivo measurements of RNA secondary structures with m6A sites (Spitale et al. 2015). Other studies, perturbing factors involved in writing or erasing m6A, have found effects on mRNA export (Fustin et al. 2013; Zheng et al. 2013) and splicing (Zhao et al. 2014). Finally, recent studies have pursued an enrichment of methylated sites around miRNAs. Studies by the Tavazoie laboratory have revealed a requirement for m6A for processing of pre-miRNAs (Alarcón et al. 2015b) and have further reported that recognition of $\mathrm{m} 6 \mathrm{~A}$ in this context is mediated by HNRNPA2B1 (Alarcón et al. 2015a). A study from the Zhou group has reported a different connection between m6A and miRNAs, namely that miRNAs are required for formation of m6A at their target sites (Chen et al. 2015).

Thus, advances in recent years have dramatically expanded our toolkit for studying m6A and have begun to expose different levels at which RNA methylations are associated with phenotypic and molecular consequences.

Nonetheless, major knowledge gaps remain to be filled. The overarching challenge is bridging the "epitranscriptotype to phenotype" gap and understanding how dysregulated methylation sites lead to the diverse phenotypes with which disruption of methylation writers/readers/erasers are associated. This question must be addressed at multiple levels. First, it will be critical to establish that the phenotypes are indeed methylation dependent and not due to secondary functions of the associated enzymes. This is particularly important, as in various cases phenotypes obtained upon deletion of RNA modifying genes are not or only partially recapitulated in catalytically dead mutants (Tollervey et al. 1993; Zebarjadian et al. 1999). In some cases RNA-modifying genes have an additional function completely unrelated 
to RNA modifications (Behm-Ansmant et al. 2004). Such appears to be the case also for $\mathrm{m} 6 \mathrm{~A}$ in meiosis, where a full deletion of the yeast methyltransferase, IME4, has a more severe phenotype than the one obtained in a catalytic mutant, suggesting that IME4 may have additional functions not directly dependent on methylation (Clancy et al. 2002; Agarwala et al. 2012).

Once it is established that a phenotype can be associated directly with RNA modifications, the next challenge will be in understanding which of the modified sites underlies the phenotype. This is particularly daunting, as there are tens of thousands of methylated sites in the mammalian transcriptome, and deciphering which of them-or which combination of them-is causally linked to a phenotype is an immense challenge. An important lesson to bear in mind in this context is ADAR2-mediated editing of adenosine to inosine. While ADAR2 deletion is lethal in mouse, and ADAR2 has tens of thousands of substrates transcriptome wide (Levanon et al. 2004; Bazak et al. 2014), the lethality stems from a single under-edited site in the GluR-B transcript, which can be reversed by substituting the under-edited alleles with ones encoding the edited version genomically (Higuchi et al. 2000). Establishing a physiological role for m6A will likely require employing a similar strategy involving point mutations in vivo at modified sites, nowadays made easier through the advent of CRISPR/Cas9 technologies (Cong et al. 2013; Mali et al. 2013). A potentially complicating factor is that it was found that point mutating an $\mathrm{m} 6 \mathrm{~A}$ site in vitro might result in accumulation of m6A at adjacent positions (Narayan et al. 1994; Bokar 2005). However, more recent work pointmutating eight methylation sites in yeast found no support for accumulation of $\mathrm{m} 6 \mathrm{~A}$ at adjacent positions in vivo, suggesting that this is a viable strategy (Schwartz et al. 2013).

It will further be crucial to understand the functions of $\mathrm{m} 6 \mathrm{~A}$. The post-transcriptional life of an mRNA is very complex, involving processing, export, subcellular localization, translation, and degradation, and these different steps-as well as the cross-talk between them-can potentially be impacted by methylation. As indicated above, research in recent years has begun to associate factors involved in methylation in many of these steps, including processing (Fustin et al. 2013; Zheng et al. 2013; Zhao et al. 2014; Alarcón et al. 2015b), export (Fustin et al. 2013; Zheng et al. 2013; Zhao et al. 2014; Alarcón et al. 2015b), destabilization (Schwartz et al. 2014b; Wang et al. 2014a,b; Geula et al. 2015), and translation (Wang et al. 2015). As these molecular effects have been observed for the most part upon perturbation of methylation-associated proteins, which potentially impact all, or a large number, of methylated sites, it will be critical to distinguish which of these effects are a direct consequence of perturbed methylation states and which of them might reflect pleiotropic effects only indirectly linked to the initial perturbation. To overcome these challenges, it will be necessary to develop approaches to directly measure the consequences of perturbing methylation states at individual sites, such as by point-mutating the modified site. Alternatively, these questions can be addressed by monitoring the RNA life cycle in relevant systems in which such dynamic modification patterns naturally exist.

In parallel, we need to better understand the mechanisms through which m6A acts and how it is embedded and regulated within the cellular circuitry. Though the discovery of the $\mathrm{m} 6 \mathrm{~A}$ readers and the impact of the modification on RNA secondary structures have been major advances in this respect, our understanding remains in its infancy. We have a very poor understanding of what happens downstream from the binding of $\mathrm{m} 6 \mathrm{~A}$ by specific readers, how and where this ties into the life cycle of an mRNA, and how this in turn impacts cellular states and cellular decision-making. Obtaining a mechanistic understanding of the factors involved in decoding $\mathrm{m} 6 \mathrm{~A}$ will provide the tools to dissect whether the distinct molecular effects (e.g., impact on stability, impact on translation) are independent of each other and whether they reflect-or allow-functional coupling of different steps in the mRNA life cycle.

In these contexts, it will be critical to understand to what extent $\mathrm{m} 6 \mathrm{~A}$ is dynamically regulated. In contrast to yeast, where methylations are highly dynamic across meiosis (Clancy et al. 2002; Agarwala et al. 2012; Schwartz et al. 2013), across most surveyed mammalian systems the topologies of methylation appear, overall, to be stable (Batista et al. 2014; Schwartz et al. 2014b; Geula et al. 2015). An important caveat in evaluating these results is that the methodologies used in these studies to map methylations all rely on immunoprecipitations using an anti-m6A antibody, which is not ideally suited for quantification of $\mathrm{m} 6 \mathrm{~A}$ stoichiometries, and therefore subtle quantitative differences in methylation stoichiometries are likely to remain undetected. For systems in which $\mathrm{m} 6 \mathrm{~A}$ is dynamic, it will be important to understand how such dynamics are achieved: Is it mediated through dynamic control of methylation writers? Or through dynamic elimination of methylations, achieved through erasers? More generally, what is the division of labor between the different writers and between the erasers?

Closely related questions remaining to be resolved pertain to the determinants of specificity at various levels: First, what underlies the catalysis of m6A at only a fraction of the sites containing an m6A consensus? Or the enrichment at specific regions within genes (Dominissini et al. 2012; Meyer et al. 2012)? While it appears that the writers act as a single complex and share the same substrates (Liu et al. 2013a; Schwartz et al. 2014b), less is understood regarding the substrates of m6A "readers" and even less regarding "erasers." Do different m6A readers bind to distinct subsets of sites, as suggested by comparing Clip-seq data sets for two m6A readers (Wang et al. 2015)? If so, how is such specificity achieved? Similarly, what are the physiological substrates of each of the two m6A erasers? Do they act on all sites, or are they restricted to a potentially very small subset of sites, as was suggested to be the case for FTO (Hess et al. 2013)? 
To help overcome these challenges, it will be crucial to further develop our toolkit for studying m6A. Mapping technologies need to be further improved, ideally to not only provide single-nucleotide resolution, as has recently been achieved (Linder et al. 2015; Ke et al. 2015), but to also allow a quantitative readout of the proportion, or stoichiometry, of methylation at all sites. Current techniques for quantifying stoichiometry are labor intensive and provide readouts only for a single site at a time (Liu et al. 2013b). It will further be necessary to come up with effective approaches to perturb modification states at individual sites. To date, this has relied on editing the genome sequence in a manner that precludes modification, such as by point-mutating the modified site. However, this strategy is not readily scalable nor does it allow distinguishing whether effects associated with the mutant are due to changing the modification state or the genome sequence.

While this review has focused on m6A, it is becoming apparent that the collection of modifications on mRNA is substantially wider. Recent advances in transcriptome-wide mapping of a different modification, pseudouridine $(\Psi)$, have revealed this modification to be present at hundreds of mRNAs in yeast and human (Carlile et al. 2014; Lovejoy et al. 2014; Schwartz et al. 2014a). Moreover, $\Psi$ was found to be dynamically modulated in different conditions, such as heat shock (Schwartz et al. 2014a) or nutrient deprivation (Carlile et al. 2014) in yeast, suggesting that it may serve as a regulatory layer. Previous studies have found 5-methylcytosine $(\mathrm{m} 5 \mathrm{C})$ to be present on some mRNAs of archaea (Edelheit et al. 2013) and human (Squires et al. 2012; Hussain et al. 2013; Khoddami and Cairns 2013). Establishing the functions of these modifications, the mechanisms through which they act and interact, and linking them to phenotypes with which their disruption is associated will require meeting similar challenges to the ones described above.

Though numerous advances have been made in recent years, our understanding of the epitranscriptome is still in its infancy. We anticipate that the coming years will give rise to many exciting insights, which will both expand our knowledge of the repertoire of modifications on mRNA and our understanding of their biological roles and the mechanisms through which they act.

\section{ACKNOWLEDGMENTS}

S.S. is supported by research grants from the Abramson Family Center for Young Scientists, the David and Fela Shapell Family Foundation INCPM Fund for Preclinical Studies, and the Estate of David Turner.

\section{REFERENCES}

Agarwala S, Blitzblau H, Hochwagen A, Fink G. 2012. RNA methylation by the MIS complex regulates a cell fate decision in yeast. PLoS Genet 8: e1002732.
Alarcón CR, Goodarzi H, Lee H, Liu X, Tavazoie S, Tavazoie SF. 2015a. HNRNPA2B1 is a mediator of $\mathrm{m}^{6} \mathrm{~A}$-dependent nuclear RNA processing events. Cell 162: 1299-1308.

Alarcón CR, Lee H, Goodarzi H, Halberg N, Tavazoie SF. 2015b. $N^{6}$-methyladenosine marks primary microRNAs for processing. Nature 519: 482-485.

Anantharaman V, Koonin EV, Aravind L. 2002. Comparative genomics and evolution of proteins involved in RNA metabolism. Nucleic Acids Res 30: 1427-1464.

Batista PJ, Molinie B, Wang J, Qu K, Zhang J, Li L, Bouley DM, Lujan E, Haddad B, Daneshvar K, et al. 2014. m ${ }^{6}$ A RNA modification controls cell fate transition in mammalian embryonic stem cells. Cell Stem Cell 15: 707-719.

Bazak L, Haviv A, Barak M, Jacob-Hirsch J, Deng P, Zhang R, Isaacs FJ, Rechavi G, Li JB, Eisenberg E, et al. 2014. A-to-I RNA editing occurs at over a hundred million genomic sites, located in a majority of human genes. Genome Res 24: 365-376.

Behm-Ansmant I, Grosjean H, Massenet S, Motorin Y, Branlant C. 2004. Pseudouridylation at position 32 of mitochondrial and cytoplasmic tRNAs requires two distinct enzymes in Saccharomyces cerevisiae. J Biol Chem 279: 52998-53006.

Bodi Z, Zhong S, Mehra S, Song J, Graham N, Li H, May S, Fray RG. 2012. Adenosine methylation in Arabidopsis mRNA is associated with the $3^{\prime}$ end and reduced levels cause developmental defects. Front Plant Sci 3: 48.

Boissel S, Reish O, Proulx K, Kawagoe-Takaki H, Sedgwick B, Yeo GS, Meyre D, Golzio C, Molinari F, Kadhom N, et al. 2009. Loss-offunction mutation in the dioxygenase-encoding FTO gene causes severe growth retardation and multiple malformations. Am J Hum Genet 85: 106-111.

Bokar JA. 2005. The biosynthesis and functional roles of methylated nucleosides in eukaryotic mRNA. In Fine-tuning of RNA functions by modification and editing (ed. Grosjean H), Vol. 12, pp. 141-177. Springer-Verlag, Berlin/Heidelberg.

Bokar JA, Shambaugh ME, Polayes D, Matera AG, Rottman FM. 1997. Purification and cDNA cloning of the AdoMet-binding subunit of the human mRNA ( $\mathrm{N}^{6}$-adenosine)-methyltransferase. RNA 3: 1233-1247.

Carlile TM, Rojas-Duran MF, Zinshteyn B, Shin H, Bartoli KM, Gilbert WV. 2014. Pseudouridine profiling reveals regulated mRNA pseudouridylation in yeast and human cells. Nature 515: 143-146.

Chen T, Hao Y-J, Zhang Y, Li M-M, Wang M, Han W, Wu Y, Lv Y, Hao J, Wang L, et al. 2015. $\mathrm{m}^{6} \mathrm{~A}$ RNA methylation is regulated by microRNAs and promotes reprogramming to pluripotency. Cell Stem Cell 16: 289-301.

Clancy M, Shambaugh M, Timpte CS, Bokar JA. 2002. Induction of sporulation in Saccharomyces cerevisiae leads to the formation of $N^{6}$-methyladenosine in mRNA: a potential mechanism for the activity of the IME4 gene. Nucleic Acids Res 30: 4509-4518.

Cohn WE, Volkin E. 1951. Nucleoside-5'-phosphates from ribonucleic acid. Nature 167: 483-484.

Cong L, Ran FA, Cox D, Lin S, Barretto R, Habib N, Hsu PD, Wu X, Jiang W, Marraffini LA, et al. 2013. Multiplex genome engineering using CRISPR/Cas systems. Science 339: 819-823.

Davis FF, Allen FW. 1957. Ribonucleic acids from yeast which contain a fifth nucleotide. J Biol Chem 227: 907-915.

Desrosiers R, Friderici K, Rottman F. 1974. Identification of methylated nucleosides in messenger RNA from Novikoff hepatoma cells. Proc Natl Acad Sci 71: 3971-3975.

Dominissini D, Moshitch-Moshkovitz S, Schwartz S, Salmon-Divon M, Ungar L, Osenberg S, Cesarkas K, Jacob-Hirsch J, Amariglio N, Kupiec M, et al. 2012. Topology of the human and mouse $\mathrm{m}^{6} \mathrm{~A}$ RNA methylomes revealed by $\mathrm{m}^{6} \mathrm{~A}$-seq. Nature 485: 201-206.

Edelheit S, Schwartz S, Mumbach MR, Wurtzel O, Sorek R. 2013. Transcriptome-wide mapping of 5-methylcytidine RNA modifications in bacteria, archaea, and yeast reveals $\mathrm{m} 5 \mathrm{C}$ within archaeal mRNAs. PLoS Genet 9: e1003602. 
Fischer J, Koch L, Emmerling C, Vierkotten J, Peters T, Brüning JC, Rüther U. 2009. Inactivation of the Fto gene protects from obesity. Nature 458: 894-898.

Fustin JM, Doi M, Yamaguchi Y, Hida H, Nishimura S, Yoshida M, Isagawa T, Morioka MS, Kakeya H, Manabe I, et al. 2013. RNAmethylation-dependent RNA processing controls the speed of the circadian clock. Cell 155: 793-806.

Geula S, Moshitch-Moshkovitz S, Dominissini D, Mansour AA, Kol N, Salmon-Divon M, Hershkovitz V, Peer E, Mor N, Manor YS, et al. 2015. Stem cells. $\mathrm{m}^{6}$ A mRNA methylation facilitates resolution of naïve pluripotency toward differentiation. Science 347: 1002-1006.

Greenberg H, Penman S. 1966. Methylation and processing of ribosomal RNA in HeLa cells. J Mol Biol 21: 527-535.

Grosjean H, Benne R, Others. 1998. Modification and editing of RNA. ASM Press, Washington DC.

He C. 2010. Grand challenge commentary: RNA epigenetics? Nat Chem Biol 6: 863-865.

Hess ME, Hess S, Meyer KD, Verhagen LAW, Koch L, Brönneke HS, Dietrich MO, Jordan SD, Saletore Y, Elemento O, et al. 2013. The fat mass and obesity associated gene (Fto) regulates activity of the dopaminergic midbrain circuitry. Nat Neurosci 16: 1042-1048.

Higuchi M, Maas S, Single FN, Hartner J, Rozov A, Burnashev N, Feldmeyer D, Sprengel R, Seeburg PH. 2000. Point mutation in an AMPA receptor gene rescues lethality in mice deficient in the RNA-editing enzyme ADAR2. Nature 406: 78-81.

Hongay CF, Orr-Weaver TL. 2011. Drosophila inducer of MEiosis 4 (IME4) is required for Notch signaling during oogenesis. Proc Natl Acad Sci 108: 14855-14860.

Horiuchi K, Umetani M, Minami T, Okayama H, Takada S, Yamamoto M, Aburatani H, Reid PC, Housman DE, Hamakubo T, et al. 2006. Wilms' tumor 1-associating protein regulates G2/M transition through stabilization of cyclin A2 mRNA. Proc Natl Acad Sci 103: 17278-17283.

Horiuchi K, Kawamura T, Iwanari H, Ohashi R, Naito M, Kodama T, Hamakubo T. 2013. Identification of Wilms' tumor 1-associating protein complex and its role in alternative splicing and the cell cycle. J Biol Chem 288: 33292-33302.

Hussain S, Sajini AA, Blanco S, Dietmann S, Lombard P, Sugimoto Y, Paramor M, Gleeson JG, Odom DT, Ule J, et al. 2013. NSun2-mediated cytosine-5 methylation of vault noncoding RNA determines its processing into regulatory small RNAs. Cell Rep 4: 255-261.

Jia G, Fu Y, Zhao X, Dai Q, Zheng G, Yang Y, Yi C, Lindahl T, Pan T, Yang Y-G, et al. 2011. N6-methyladenosine in nuclear RNA is a major substrate of the obesity-associated FTO. Nat Chem Biol 7: 885-887.

Kang H-J, Chang M, Kang C-M, Park Y-S, Yoon B-J, Kim T-H, Yun CW. 2014. The expression of PHO92 is regulated by Gcr1, and Pho92 is involved in glucose metabolism in Saccharomyces cerevisiae. Curr Genet 60: 247-253.

Ke S, Alemu EA, Mertens C, Gantman EC, Fak JJ, Mele A, Haripal B, Zucker-Scharff I, Moore MJ, Park CY, et al. 2015. A majority of $\mathrm{m}^{6} \mathrm{~A}$ residues are in the last exons, allowing the potential for $3^{\prime}$ UTR regulation. Genes Dev 29: 2037-2053.

Khoddami V, Cairns BR. 2013. Identification of direct targets and modified bases of RNA cytosine methyltransferases. Nat Biotechnol 31: 458-464.

Lavi S, Shatkin AJ. 1975. Methylated simian virus 40-specific RNA from nuclei and cytoplasm of infected BSC-1 cells. Proc Natl Acad Sci 72: 2012-2016.

Levanon EY, Eisenberg E, Yelin R, Nemzer S, Hallegger M, Shemesh R, Fligelman ZY, Shoshan A, Pollock SR, Sztybel D, et al. 2004. Systematic identification of abundant A-to-I editing sites in the human transcriptome. Nat Biotechnol 22: 1001-1005.

Li F, Zhao D, Wu J, Shi Y. 2014. Structure of the YTH domain of human YTHDF2 in complex with an $\mathrm{m}^{6} \mathrm{~A}$ mononucleotide reveals an aromatic cage for $\mathrm{m}^{6} \mathrm{~A}$ recognition. Cell Res 24: 1490-1492.
Linder B, Grozhik AV, Olarerin-George AO, Meydan C, Mason CE, Jaffrey SR. 2015. Single-nucleotide-resolution mapping of $\mathrm{m}^{6} \mathrm{~A}$ and $\mathrm{m}^{6} \mathrm{Am}$ throughout the transcriptome. Nat Methods 12: 767-772.

Liu J, Yue Y, Han D, Wang X, Fu Y, Zhang L, Jia G, Yu M, Lu Z, Deng X, et al. 2013a. A METTL3-METTL14 complex mediates mammalian nuclear RNA $N^{6}$-adenosine methylation. Nat Chem Biol 10: 93-95.

Liu N, Parisien M, Dai Q, Zheng G, He C, Pan T. 2013b. Probing $N^{6}$-methyladenosine RNA modification status at single nucleotide resolution in mRNA and long noncoding RNA. RNA 19: 1848-1856.

Liu N, Dai Q, Zheng G, He C, Parisien M, Pan T. 2015. $N^{6}$-methyladenosine-dependent RNA structural switches regulate RNA-protein interactions. Nature 518: 560-564.

Lovejoy AF, Riordan DP, Brown PO. 2014. Transcriptome-wide mapping of pseudouridines: pseudouridine synthases modify specific mRNAs in S. cerevisiae. PLoS One 9: e110799.

Machnicka MA, Milanowska K, Osman Oglou O, Purta E, Kurkowska M, Olchowik A, Januszewski W, Kalinowski S, DuninHorkawicz S, Rother KM, et al. 2013. MODOMICS: a database of RNA modification pathways-2013 update. Nucleic Acids Res 41: D262-D267.

Mali P, Yang L, Esvelt KM, Aach J, Guell M, DiCarlo JE, Norville JE, Church GM. 2013. RNA-guided human genome engineering via Cas9. Science 339: 823-826.

Meyer KD, Saletore Y, Zumbo P, Elemento O, Mason CE, Jaffrey SR. 2012. Comprehensive analysis of mRNA methylation reveals enrichment in 3' UTRs and near stop codons. Cell 149: 1635-1646.

Narayan P, Ludwiczak RL, Goodwin EC, Rottman FM. 1994. Context effects on $\mathrm{N}^{6}$-adenosine methylation sites in prolactin mRNA. Nucleic Acids Res 22: 419-426.

Perry RP, Kelley DE. 1974. Existence of methylated messenger RNA in mouse L cells. Cell 1: 37-42.

Ping X-L, Sun B-F, Wang L, Xiao W, Yang X, Wang W-J, Adhikari S, Shi Y, Lv Y, Chen Y-S, et al. 2014. Mammalian WTAP is a regulatory subunit of the RNA N6-methyladenosine methyltransferase. Cell Res 24: $177-189$.

Saletore Y, Meyer K, Korlach J, Vilfan ID, Jaffrey S, Mason CE. 2012. The birth of the epitranscriptome: deciphering the function of RNA modifications. Genome Biol 13: 175.

Schwartz S, Agarwala SD, Mumbach MR, Jovanovic M, Mertins P, Shishkin A, Tabach Y, Mikkelsen TS, Satija R, Ruvkun G, et al. 2013. High-resolution mapping reveals a conserved, widespread, dynamic mRNA methylation program in yeast meiosis. Cell 155: 1409-1421.

Schwartz S, Bernstein DA, Mumbach MR, Jovanovic M, Herbst RH, León-Ricardo BX, Engreitz JM, Guttman M, Satija R, Lander ES, et al. 2014a. Transcriptome-wide mapping reveals widespread dynamic-regulated pseudouridylation of ncRNA and mRNA. Cell 159: $148-162$.

Schwartz S, Mumbach MR, Jovanovic M, Wang T, Maciag K, Bushkin GG, Mertins P, Ter-Ovanesyan D, Habib N, Cacchiarelli D, et al. 2014b. Perturbation of m6A writers reveals two distinct classes of mRNA methylation at internal and 5' sites. Cell Rep 8: 284-296.

Shah JC, Clancy MJ. 1992. IME4, a gene that mediates MAT and nutritional control of meiosis in Saccharomyces cerevisiae. Mol Cell Biol 12: $1078-1086$.

Spitale RC, Flynn RA, Zhang QC, Crisalli P, Lee B, Jung JW, Kuchelmeister HY, Batista PJ, Torre EA, Kool ET, et al. 2015. Structural imprints in vivo decode RNA regulatory mechanisms. Nature 519: 486-490.

Squires J, Patel H, Nousch M, Sibbritt T, Humphreys D, Parker B, Suter C, Preiss T. 2012. Widespread occurrence of 5-methylcytosine in human coding and non-coding RNA. Nucleic Acids Res 40: 5023-5033.

Tollervey D, Lehtonen H, Jansen R, Kern H, Hurt EC. 1993. Temperature-sensitive mutations demonstrate roles for yeast fibrillarin in pre-rRNA processing, pre-rRNA methylation, and ribosome assembly. Cell 72: 443-457. 
Wang X, Lu Z, Gomez A, Hon GC, Yue Y, Han D, Fu Y, Parisien M, Dai Q, Jia G, et al. 2014a. $N^{6}$-methyladenosine-dependent regulation of messenger RNA stability. Nature 505: 117-120.

Wang Y, Li Y, Toth JI, Petroski MD, Zhang Z, Zhao JC. 2014b. $N^{6}$-methyladenosine modification destabilizes developmental regulators in embryonic stem cells. Nat Cell Biol 16: 191-198.

Wang X, Zhao BS, Roundtree IA, Lu Z, Han D, Ma H, Weng X, Chen K, Shi H, He C. 2015. $N^{6}$-methyladenosine modulates messenger RNA translation efficiency. Cell 161: 1388-1399.

Wei CM, Gershowitz A, Moss B. 1975. Methylated nucleotides block $5^{\prime}$ terminus of HeLa cell messenger RNA. Cell 4: 379-386.

Wei CM, Gershowitz A, Moss B. 1976.5' -Terminal and internal methylated nucleotide sequences in HeLa cell mRNA. Biochemistry 15: 397-401.

Zebarjadian Y, King T, Fournier MJ, Clarke L, Carbon J. 1999. Point mutations in yeast CBF5 can abolish in vivo pseudouridylation of rRNA. Mol Cell Biol 19: 7461-7472.
Zhao X, Yang Y, Sun B-F, Shi Y, Yang X, Xiao W, Hao Y-J, Ping X-L, Chen Y-S, Wang W-J, et al. 2014. FTO-dependent demethylation of N6-methyladenosine regulates mRNA splicing and is required for adipogenesis. Cell Res 24: 1403-1419.

Zheng G, Dahl JA, Niu Y, Fedorcsak P, Huang CM, Li CJ, Vågbø CB, Shi Y, Wang WL, Song SH, et al. 2013. ALKBH5 is a mammalian RNA demethylase that impacts RNA metabolism and mouse fertility. Mol Cell 49: 18-29.

Zhong S, Li H, Bodi Z, Button J, Vespa L, Herzog M, Fray RG. 2008. MTA is an Arabidopsis messenger RNA adenosine methylase and interacts with a homolog of a sex-specific splicing factor. Plant Cell 20: 1278-1288.

Zhu T, Roundtree IA, Wang P, Wang X, Wang L, Sun C, Tian Y, Li J, $\mathrm{He} \mathrm{C}, \mathrm{Xu}$ Y. 2014. Crystal structure of the YTH domain of YTHDF2 reveals mechanism for recognition of N6-methyladenosine. Cell Res 24: 1493-1496. 

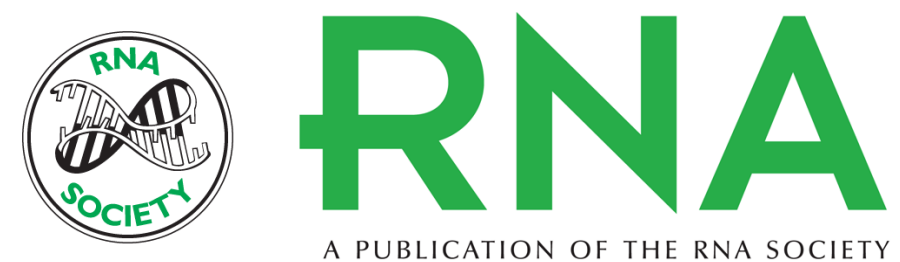

A PUBLICATION OF THE RNA SOCIETY

\section{Cracking the epitranscriptome}

Schraga Schwartz

RNA 2016 22: 169-174

References This article cites 66 articles, 17 of which can be accessed free at: http://rnajournal.cshlp.org/content/22/2/169.full.html\#ref-list-1

Creative This article is distributed exclusively by the RNA Society for the first 12 months after the Commons full-issue publication date (see http://rnajournal.cshlp.org/site/misc/terms.xhtml). After 12 License months, it is available under a Creative Commons License (Attribution-NonCommercial 4.0 International), as described at http://creativecommons.org/licenses/by-nc/4.0/.

Email Alerting Receive free email alerts when new articles cite this article - sign up in the box at the Service top right corner of the article or click here.

To subscribe to $R N A$ go to:

http://rnajournal.cshlp.org/subscriptions

(C) 2016 Schwartz; Published by Cold Spring Harbor Laboratory Press for the RNA Society 